\title{
A CLINICAL AND BACTERIOLOGICAL STUDY OF PRIMARY PYODERMAS IN CHILDREN
}

\author{
Abarna Muthulakshmi M11, K. Abdul Samad², Joan Felicita Samson ${ }^{3}$ \\ 1 Junior Resident, Department of Dermatology and Venereology, Government Medical College, Trivandrum, Kerala, India. \\ ${ }^{2}$ Additional Professor, Department of Dermatology and Venereology, Government Medical College, Trivandrum, Kerala, India. \\ ${ }^{3}$ Professor, Department of Dermatology and Venereology, Dr. Somervell Memorial CSI Medical College, Karakonam, Trivandrum, \\ Kerala.
}

\section{ABSTRACT}

\section{BACKGROUND}

Primary pyodermas are important and common public health problem in all sectors of the society, especially among the lower stratum in developing countries. This study was undertaken with the primary aims of studying the clinical profile of primary pyodermas in children and studying the bacteriological profile and antibiotic sensitivity.

\section{MATERIALS AND METHODS}

This study was a descriptive study undertaken in the Department of Dermatology and Venereology, Medical College Hospital, Thiruvananthapuram, South India, for a period of one year. The sample population included were children between 1 to 12 years who attended the outpatient wing of the department with clinical diagnosis of primary pyoderma. Clinical examination supported by Gram stain and culture with antibiotic sensitivity were the main methods to identify the causative agent and probable treatment option. Kappa co-efficient was used to measure the agreement between two diagnostic tests, Gram stain and culture.

\section{RESULTS}

The study population included 100 patients of the age group 1 - 12 years. The commonest type of primary pyoderma was impetigo. Gram staining was positive in 78 cases and culture yielded the probable causative agent in 84 cases. Staph. aureus was the commonest organism isolated in culture in 68 cases; $71.43 \%$ of Staph. aureus was sensitive to methicillin, whereas $9.52 \%$ were methicillin resistant. Methicillin sensitive Staph. aureus was sensitive to cloxacillin in $100 \%$ of the isolates. The MRSA isolates were sensitive to vancomycin, amikacin and linezolid.

\section{CONCLUSION}

Impetigo was the commonest type of pyoderma observed in the population studied. Lymphocytosis rather than neutrophilia and low frequency of raised ASO titre in streptococcal pyodermas were the unusual results obtained from this study. Methicillin sensitive Staph. aureus was the commonest aetiological agent prevalent in the population studied and there was $100 \%$ sensitivity of this agent to cloxacillin was observed. Also, the substantial agreement between Gram stain and culture highlights the importance of Gram stain in aetiological diagnosis in resource poor settings.

\section{KEYWORDS}

Primary Pyodermas, Gram Stain, Methicillin Sensitive Staph. aureus, MRSA.

HOW TO CITE THIS ARTICLE: Muthulakshmi AM, Samad KA, Samson JF. A clinical and bacteriological study of primary pyodermas in children. J. Evolution Med. Dent. Sci. 2017;6(49):3751-3756, DOI: 10.14260/Jemds/2017/811

\begin{abstract}
BACKGROUND
The primary bacterial infections of skin have a characteristic morphology and course and are incited initially by a single organism and in contrast to secondary infections originate in normal skin. Majority of the cutaneous bacterial infections are caused by either Staphylococcus aureus or Group A Streptococcus. ${ }^{1}$ The various risk factors include antecedent cutaneous lesions, obesity, steroid and other therapeutic agents, acquired or inherited immune dysfunction, malnutrition, diabetes, etc. ${ }^{2}$ They are the most common infections encountered in the paediatric age group, especially in developing countries.
\end{abstract}

Financial or Other, Competing Interest: None.

Submission 29-05-2017, Peer Review 10-06-2017,

Acceptance 12-06-2017, Published 19-06-2017.

Corresponding Author:

Dr. Abdul Samad K,

Additional Professor,

Department of Dermatology and Venereology,

Government Medical College,

Trivandrum-695011,

Kerala, India

E-mail:drsamad1961@yahoo.co.in

DOI: $10.14260 /$ jemds $/ 2017 / 811$
Recurrent pyoderma like impetigo with or without underlying dermatological disorders or immunodeficiency are common in infants and children all over the world and constitute one of the prime causes of hospital attendance in children. $^{3}$ Antibiotic resistance has become a clinically important consideration in many infections and Methicillin Resistant Staphylococcus aureus (MRSA) infection, which has been a nosocomial problem for years is now a common community acquired skin infection. ${ }^{4}$ It would be ideal to do culture and sensitivity tests before prescribing antibiotics, but as this is not always feasible studies should be conducted to determine the aetiological agents and antibiotic resistance. ${ }^{5}$

In the current settings, there are no appropriate studies regarding the epidemiological and clinical aspects of childhood impetigo in our society. Also, the studies regarding the exact aetiological agents and their antibiotic susceptibility are not well studied. At this juncture, it was decided to undertake a study to correctly elucidate the epidemiological, clinical and bacteriological aspect of primary pyodermas mainly in children. This study was undertaken with the following aims- 
1. To study the clinical profile of primary pyodermas in children.

2. To study the bacteriological profile and antibiotic sensitivity.

\section{MATERIALS AND METHODS}

This study was a descriptive study undertaken in the Department of Dermatology and Venereology, Medical College Hospital, Thiruvananthapuram, South India for a period of one year. The sample population included children between 1 to 12 years who attended the outpatient wing of the department with clinical diagnosis of primary pyoderma. The sample size anticipated was 100. All children with primary pyoderma who were started on topical and systemic antibiotics were excluded. Informed consent was obtained from the parents. A detailed history was taken including socioeconomic status, personal hygiene, history of debilitating illnesses and history of medications. The main investigations included complete blood count, liver and renal function tests, antistreptolysin 0 titre, random blood sugar, 24-hour urine protein and gram stain and culture and sensitivity of pus from the lesions. Pus culture was done on blood agar and MacConkey's agar with incubation at $37^{\circ} \mathrm{C}$ for 48 hours. Organisms grown were identified based on the basis of their morphology, cultural characteristics and biochemical reactions according to the standard methods. Sensitivity of the organisms to antibiotics was tested on Mueller-Hinton agar and by disc diffusion technique using Kirby-Bauer method.

Statistical analysis of the data was done using an appropriate computer software and the data was expressed in frequency and percentage. Chi-square test was used to assess statistical significance and a 'p' value of $<0.05$ was taken as statistically significant. Kappa co-efficient was used to measure the agreement between the two diagnostic tools, Gram staining and culture. The scale of interpretation of the measure of agreement based on kappa values were as follows:

\begin{tabular}{|c|c|}
\hline Kappa Value & Measure of Agreement \\
\hline $0-0.2$ & Slight \\
\hline $0.2-0.4$ & Fair \\
\hline $0.4-0.6$ & Moderate \\
\hline $0.6-0.8$ & Substantial \\
\hline $0.8-1$ & Almost Perfect \\
\hline
\end{tabular}

\section{RESULTS}

The study population included 100 patients belonging to the age group of 1 to 12 years of both sexes, who attended the outpatient wing of the Department of Dermatology and Venereology of Medical College, Thiruvananthapuram. The study period was one year. The mean age of the study population was 4.62 years; 56 children belonged to the age group of 1 to 4 years and 44 children belonged to the age group of 5 to 12 years; 70 patients were males and 30 were females. Majority of the children (64) belonged to the lower socio-economic group according to the Kuppuswamy scale of socioeconomic status and 36 children belonged to the middle socioeconomic stratum. Nutritional status as assessed by the Indian Association of Paediatric norms showed adequate nourishment in 76 patients and malnourishment in 24 patients. Personal hygiene as assessed by the habit of daily bathing and changing clothes showed good personal hygiene in all the patients. Predisposing factors for bacterial infections were not observed in the majority (96\%), while 2 children were atopic and another 2 children had nephrotic syndrome.

Focus of infections were noticed in 38 patients, which included caries teeth in 14 patients, tonsillitis in 10 patients, upper respiratory infection in 6 patients and otitis media in 4 patients. Otitis media and caries teeth were present in 2 children and otitis media with upper respiratory tract infection was seen in another 2 children. There were no foci of infection in the majority of the patients (62\%) (Table 1).

\begin{tabular}{|c|c|c|}
\hline Focus of Infection & Frequency & Percentage \\
\hline Caries Teeth & 14 & 14 \\
\hline Tonsillitis & 10 & 10 \\
\hline Upper Respiratory Tract Infection & 06 & 06 \\
\hline Otitis Media & 04 & 04 \\
\hline Otitis Media + Caries Teeth & 02 & 02 \\
\hline $\begin{array}{c}\text { Otitis Media + Upper Respiratory } \\
\text { Tract Infection }\end{array}$ & 02 & 02 \\
\hline No Focus of Infection & 62 & 62 \\
\hline Total & $\mathbf{1 0 0}$ & $\mathbf{1 0 0}$ \\
\hline \multicolumn{2}{|c|}{ Table 1. Showing Foci of Infection } \\
\hline
\end{tabular}

Regional lymphadenopathy was seen in 52 patients and in the remaining 48 patients it was absent. It was most commonly observed in 40 patients with impetigo contagiosa.

Commonest site of skin lesions was extremities in 36 patients followed by head and neck in 20 patients and a combination of both these sites in 22 patients. Both trunk and extremities were involved in 12 patients (Table 2).

\begin{tabular}{|c|c|c|}
\hline Distribution of Lesions & Frequency & Percentage \\
\hline Extremities & 36 & 36 \\
\hline Head and Neck & 20 & 20 \\
\hline Head and Neck + Extremities & 22 & 22 \\
\hline Trunk and Extremities & 12 & 12 \\
\hline $\begin{array}{c}\text { Head and Neck + Extremities + } \\
\text { Trunk }\end{array}$ & 06 & 06 \\
\hline $\begin{array}{c}\text { Extremities + Genitalia } \\
\text { Head and Neck + Trunk }\end{array}$ & 02 & 02 \\
\hline Total & $\mathbf{1 0 0}$ & 02 \\
\hline Table 2. Distribution of Skin Lesions \\
\hline
\end{tabular}

Examination of all the systems were normal except that 1 child had nephrotic syndrome and another one had a past history of nephrotic syndrome.

\section{Clinical Diagnosis}

The commonest type of primary pyoderma was impetigo seen in 80 cases. Among this impetigo contagiosa was the diagnosis in 76 patients and bullous impetigo in 4 patients. The other diagnoses were folliculitis in 10 patients, furuncle in 8 patients and ecthyma in 2 patients (Table 3 ).

\begin{tabular}{|c|c|c|}
\hline Clinical Diagnosis & Frequency & Percentage \\
\hline Impetigo contagiosa & 76 & 76 \\
\hline Folliculitis & 10 & 10 \\
\hline Furuncle & 08 & 08 \\
\hline Bullous Impetigo & 04 & 04 \\
\hline Ecthyma & 02 & 02 \\
\hline Total & $\mathbf{1 0 0}$ & $\mathbf{1 0 0}$ \\
\hline \multicolumn{2}{|c|}{ Table 3. Clinical Diagnosis } \\
\hline
\end{tabular}




\section{Investigations}

Routine blood investigations showed leucocytosis in 42 cases, neutrophilia in 18 cases, lymphocytosis in 70 cases and elevated ESR in 42 cases. ASO titre was positive in 2 patients, both patients having impetigo contagiosa and one patient had an associated tonsillitis also. Renal function tests were normal in all the patients. Routine urine examination showed albuminuria in 4 patients and urine sugar $1.5 \%$ in 1 patient; 24-hour urine protein estimation was done in all patients and was within normal range in all patients.
Gram staining for organisms was positive in 78 cases. All these patients had gram positive cocci and one patient showed gram negative bacilli along with gram positive cocci. Polymorphonuclear leucocytes as pus cells were seen in 82 cases and in 64 of these patients showed pus cells along with gram positive cocci.

Out of all the 100 cases, culture was positive in 84 cases and it was sterile in 16 cases after 48 hours of incubation. Among the culture positive cases 72 cases had isolation of single organism and 12 cases had mixed growth. Staphylococcus aureus was the commonest organism isolated in 68 cases $(80.95 \%$ of the culture positive cases). Streptococcus pyogenes and Escherichia coli were isolated in 2 cases each (Table 4).

\begin{tabular}{|c|c|c|}
\hline Organisms Isolated in Culture & Frequency & Percentage in Culture Positive Cases \\
\hline Staphylococcus aureus & 68 & 80.95 \\
\hline Streptococcus pyogenes & 02 & 02.38 \\
\hline Escherichia coli & 02 & 02.38 \\
\hline Mixed organisms & 12 & 14.29 \\
\hline Total & $\mathbf{8 4}$ & $\mathbf{1 0 0}$ \\
\hline \multicolumn{2}{|c|}{ Table 4. Culture Positivity } \\
\hline
\end{tabular}

Out of the 68 isolates of Staph. aureus, 60 were sensitive to methicillin $(71.43 \%)$ and the remaining 8 were methicillin resistant Staph. aureus (9.52\%). Among the 12 cases of mixed organism isolates, Staph. aureus was isolated along with Streptococcus pyogenes in 4 cases and with Pseudomonas aeruginosa and Klebsiella sp. in 2 cases each.

\section{Correlation of Culture with Clinical Diagnosis}

Methicillin sensitive Staph. aureus was the most common organism isolated from impetigo contagiosa lesions in 50 cases $(67.89 \%)$ followed by methicillin resistant Staph. aureus in 6 cases (7.89\%), a combination of Staph. aureus and Streptococcus pyogenes in 4 cases $(5.26 \%)$ and Streptococcus pyogenes alone in 2 cases $(2.63 \%)$. Out of the 4 bullous impetigo cases, Staph. aureus was isolated from 2 cases and mixed organisms from 2 cases. Out of the 10 cases of folliculitis, methicillin sensitive Staph. aureus was the most common isolate in 4 cases (40\%) and MRSA, E. coli and mixed organisms in 2 cases each. Among the 8 cases of furuncles, Staph. aureus was isolated from 4 cases (50\%) and the culture was sterile in the remaining 4 cases. The culture was sterile in both cases of ecthyma (Table 5).

\begin{tabular}{|c|c|c|c|c|c|}
\hline Clinical Diagnosis & $\begin{array}{l}\text { Methicillin Sensitive } \\
\text { Staph. aureus }\end{array}$ & MRSA & $\begin{array}{l}\text { Streptococcus } \\
\text { Pyogenes }\end{array}$ & Others & No Organisms \\
\hline $\begin{array}{l}\text { Impetigo contagiosa } \\
\qquad(\mathrm{n}=76)\end{array}$ & $50(65.79 \%)$ & $06(7.89 \%)$ & $02(2.63 \%)$ & $\begin{array}{c}\text { Staph. aureus + Strept. pyogenes } \\
04(5.26 \%) \\
\text { Staph. Aureus + Ps. aeruginosa } \\
02(2.63 \%) \\
\\
\text { Staph. aureus + Klebsiella sp. } \\
02(2.63 \%)\end{array}$ & 10 (13.17\%) \\
\hline $\begin{array}{l}\text { Bullous impetigo } \\
(\mathrm{n}=04)\end{array}$ & $02(50 \%)$ & - & - & $\begin{array}{c}\text { Mixed organisms } \\
02(50 \%)\end{array}$ & - \\
\hline Folliculitis $(n=10)$ & $04(40 \%)$ & $02(20 \%)$ & - & $\begin{array}{l}\text { Mixed organisms } \\
02(20 \%) \\
\text { Escherichia coli } \\
02(20 \%)\end{array}$ & - \\
\hline Furuncle $(\mathrm{n}=08)$ & $04(50 \%)$ & - & - & - & $04(50 \%)$ \\
\hline Ecthyma $(\mathrm{n}=02)$ & - & - & - & - & $02(100 \%)$ \\
\hline
\end{tabular}

\section{Antibiotic Sensitivity Pattern of Culture Organism}

Staph. aureus was sensitive to cloxacillin in all the 68 cases (100\%), first generation cephalosporin in 64 cases (94.11\%), amikacin in 50 cases (73.53\%), gentamicin in 40 cases (58.82\%) and erythromycin in 16 cases (23.53\%). It was resistant to penicillin in 66 
out of the 68 cases (97.06\%), to erythromycin in 52 cases (76.47\%), to amikacin in 18 cases (26.47\%), to gentamicin in 28 cases $(41.18 \%)$ and $1^{\text {st }}$ generation cephalosporin in 4 cases $(5.88 \%)$. MRSA was resistant to cloxacillin, penicillin and first generation cephalosporin in all the 6 cases (100\%) and to gentamicin in 4 cases (66.67\%). E. coli was resistant to ciprofloxacin, first generation cephalosporin and ampicillin (Table 6).

\begin{tabular}{|c|c|c|c|c|c|c|}
\hline Drug & $\begin{array}{c}\text { St. aureus } \\
(n=68)\end{array}$ & $\begin{array}{c}\text { MRSA } \\
(n=06)\end{array}$ & $\begin{array}{c}\text { Str. pyogenes } \\
(n=06)\end{array}$ & Ps. aeruginosa & $\begin{array}{l}\text { Klebsiella } \\
\text { sp. }\end{array}$ & E. coli \\
\hline Penicillin & $66(97.06 \%)$ & $06(100 \%)$ & - & - & - & - \\
\hline Gentamicin & $28(41.18 \%)$ & $04(66.67 \%)$ & - & - & - & - \\
\hline Amikacin & $18(26.47 \%)$ & - & - & - & - & - \\
\hline Cloxacillin & - & $06(100 \%)$ & - & - & - & - \\
\hline Erythromycin & $52(76.47 \%)$ & - & - & - & - & - \\
\hline Ciprofloxacin & - & - & - & - & - & $02(100 \%)$ \\
\hline $\begin{array}{l}1^{\text {st }} \text { Generation } \\
\text { Cephalosporin }\end{array}$ & $04(5.88 \%)$ & $06(100 \%)$ & - & - & - & $02(100 \%)$ \\
\hline Ampicillin & - & - & - & - & - & $02(100 \%)$ \\
\hline
\end{tabular}

Agreement between Gram Stain and Culture

The agreement between the 2 diagnostic tests was analysed using Cohen's kappa coefficient (Table 7).

\begin{tabular}{|c|c|c|c|}
\hline & \multicolumn{2}{|c|}{ Culture } & \multirow{2}{*}{ Total } \\
\cline { 2 - 4 } & Positive & Negative & \\
\hline Gram Stain & & & 78 \\
Positive & 76 & 02 & 22 \\
Negative & 08 & 14 & $\mathbf{1 0 0}$ \\
\hline Total & $\mathbf{8 4}$ & $\mathbf{1 6}$ & \multicolumn{1}{|c|}{ Table 7. Agreement between Gram Stain and Culture } \\
\hline \multicolumn{2}{|c}{}
\end{tabular}

Thus, 76 patients were gram stain positive, were culture positive also and 14 patients were both gram stain and culture negative. So an agreement between Gram stain and culture were seen in 90 cases $(76+14)$. Both the tests were discordant in 10 cases.
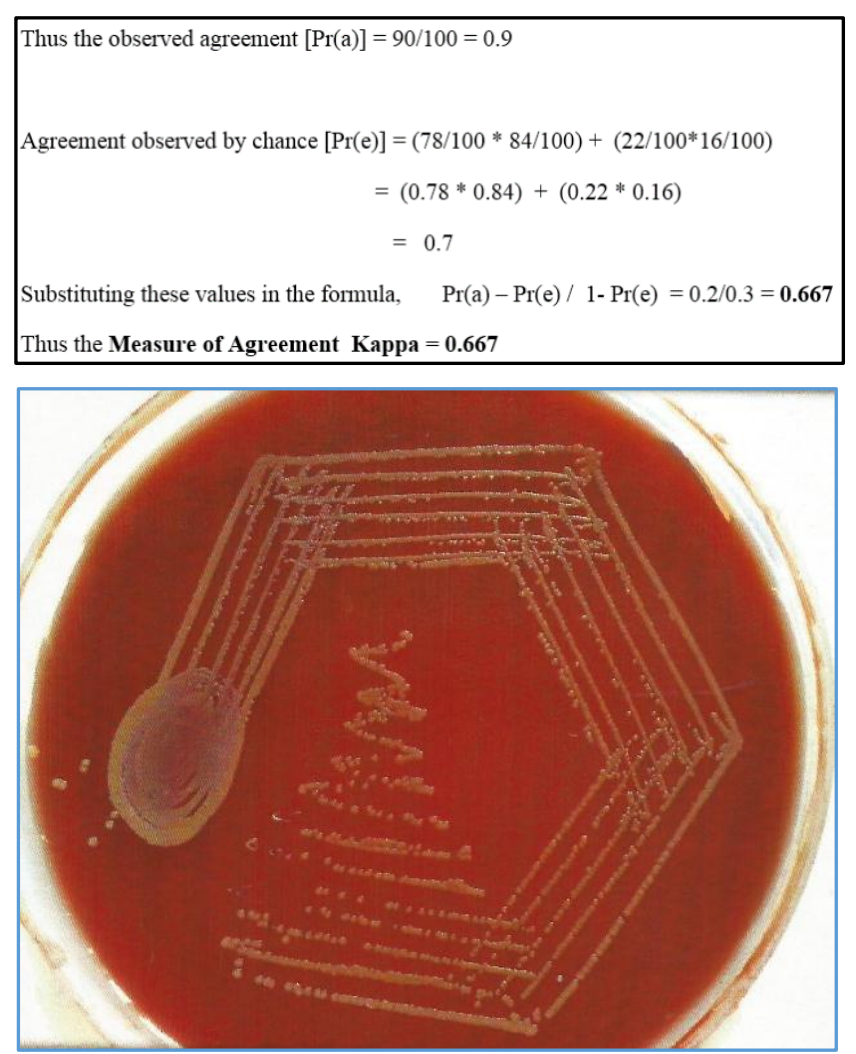

Image 1. Blood agar showing Golden Yellow Colonies of Staphylococcus aureus

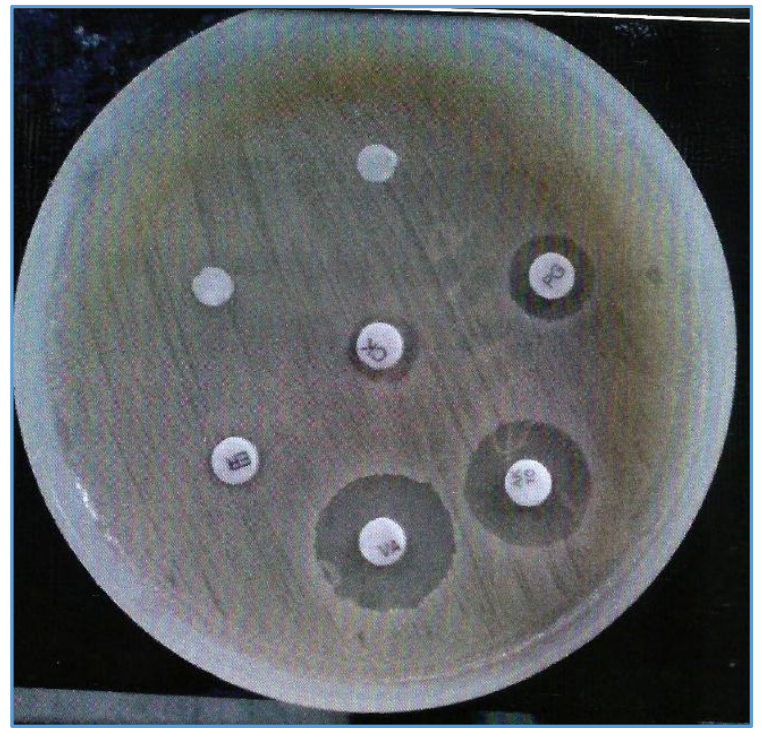

Image 2. Antibiotic Sensitivity of Staphylococcus aureus (Kirby-Bauer Method)

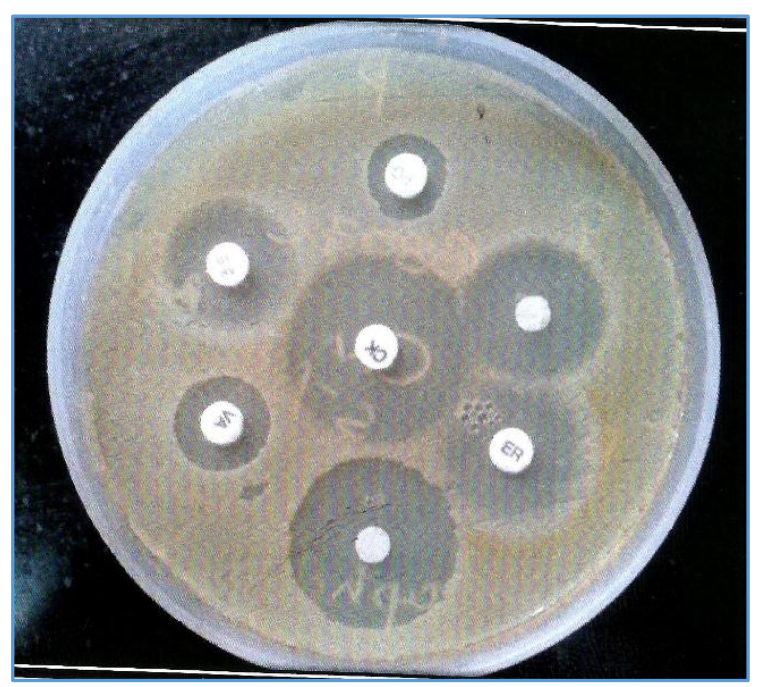

Image 3. Antibiotic Sensitivity Test showing MRSA 


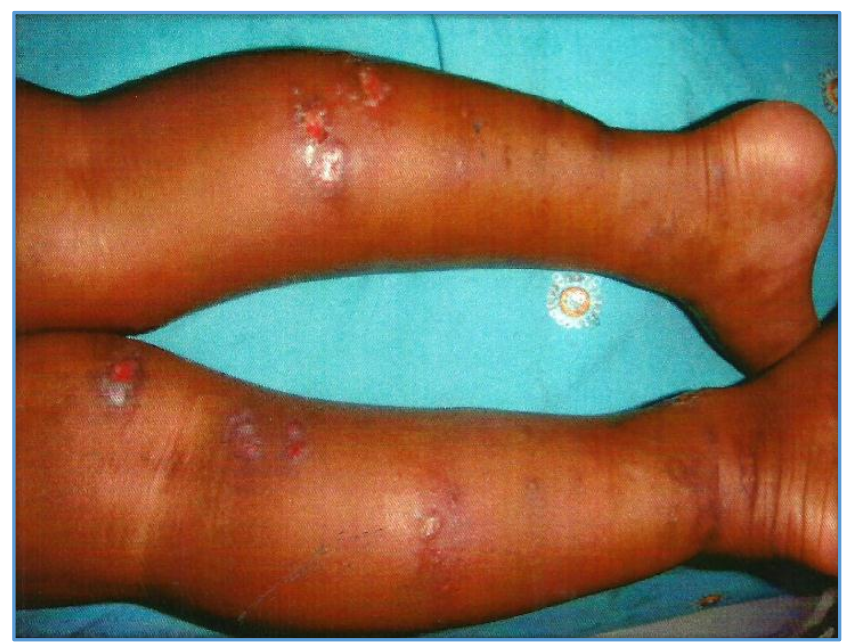

Image 4. Impetigo Contagiosa Lesions over Lower Extremities

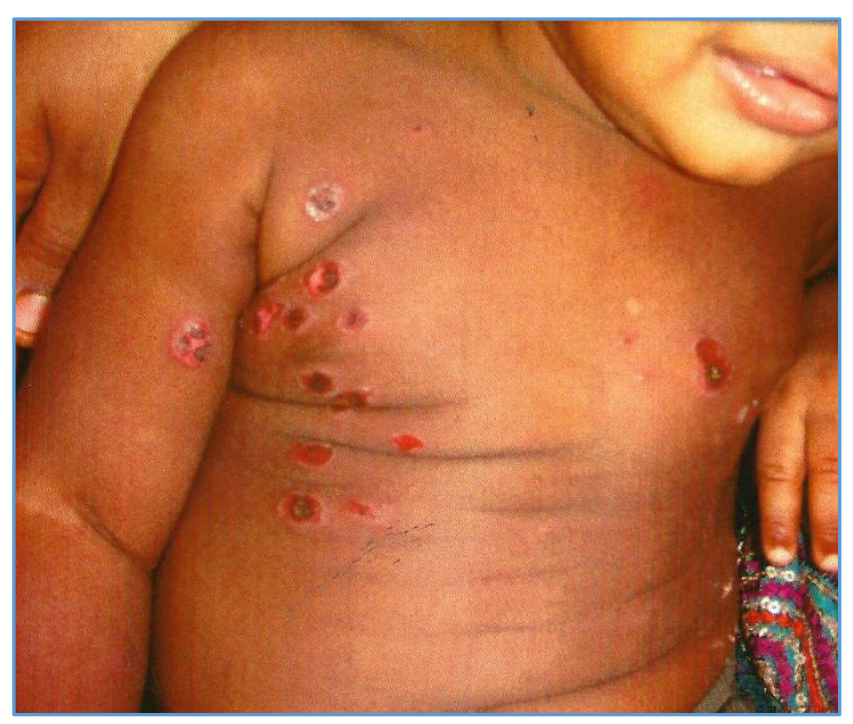

Image 5. Bullous Impetigo Lesions over Trunk and Upper Limb

\section{DISCUSSION}

This study on the clinical and bacteriological aspects of primary pyoderma in children showed a high predominance in the age group of 1 to 4 years (56\%). This was similar to the pattern seen in studies conducted in Pondicherry, Belgaum and Delhi.5,6,7 This susceptibility to bacterial infections in this age group is due to the decreased immunity to infective agents. The male-to-female sex ratio of 1.94: 1 is similar to that observed by Kharel $\mathrm{C}$ et $\mathrm{al}^{8}$ showing slight male preponderance. Majority of the children (64\%) was from low socio-economic status, which was also similar to previous similar studies.7,8 Poor hygiene and low standards of living are obviously the predisposing factors of pyoderma in children. However, the observation of good personal hygiene in all the 100 cases stands in contrary to this in this particular study. Though under nourishment was considered a predisposing factor, it was observed only in $24 \%$ of cases. Commonest focus of infection observed was caries teeth in $14 \%$ cases and tonsillitis in $10 \%$ cases, which were more frequently associated with impetigo contagiosa.

Regional lymphadenopathy observed in $52 \%$ of cases were mainly in patients with extensive impetigo contagiosa and that was the predominant type of pyoderma invading the lymphatic system. Systemic examination in all patients did not show any other form of systemic involvement in any of the cases.

Impetigo contagiosa was the commonest clinical type of pyoderma encountered in $76 \%$ of the patients. This was so in both boys $(77 \%)$ and girls $(73 \%)$. The next common primary pyoderma was folliculitis $(10 \%)$ followed by furuncle $(8 \%)$, bullous impetigo (4\%) and ecthyma (2\%). Studies by Mathew $\mathrm{S}$ et al, ${ }^{5}$ Kar PK et $\mathrm{al}^{9}$ also showed similar observations.

Leucocytosis was found in $42 \%$ of cases in this study, whereas it was of a lower frequency in many other studies as observed by Ahamed K et al.10 Lymphocytosis (in 70\%) and raised ESR (in 42\%) were the other important haematological observations. In contrary to expectations, neutrophilia was observed in $18 \%$ cases only. Raised ASO titre was seen only in one patient, that was in a patient with staphylococcal pyoderma and all the 6 cases of streptococcal pyoderma did not show rise in ASO titre.

Gram staining was positive in $78 \%$ cases and the commonest organisms were gram positive cocci. Culture positivity in this study was $84 \%$. This was similar to the studies by Patil R et al (83.7\%) ${ }^{11}$ and Tushar S et al (83\%). ${ }^{12}$ Single organism was isolated in $85.71 \%$ of cases and mixed growth in $14.29 \%$ of cases. This pattern was similar to that observed by Nagmoti MJ et al ${ }^{6}$ ( $86 \%$ and $14 \%$ ) and Kakar N et $\mathrm{al}^{7}$ (84\% and 16\%). Commonest organism isolated was Staphylococcus aureus in $80.95 \%$ with low percentages of Streptococcus pyogenes (2.38\%) and Escherichia coli $(2.38 \%)$. This is against the study by Nagmoti et al, where S. aureus was isolated in $45 \%$ cases and streptococcus and E. coli in $35 \%$ and $5 \%$ respectively. This may point to either a low prevalence of streptococcal infection in the population studied or a poor culture technology for isolating streptococci.

The observation of methicillin resistant S. aureus in $9.52 \%$ of the study population is similar to that observed by Tushar S et al (10.45\%). But various other studies in India showed varying percentages of MRSA ranging from $1.4 \%$ to $32 \%$.

On correlation of culture pattern with clinical diagnosis, the striking observation was that methicillin sensitive staphylococci was the predominant organism in $67.89 \%$ of impetigo contagiosa cases, $50 \%$ of bullous impetigo cases, $40 \%$ of folliculitis cases and $50 \%$ of furuncle cases. Thus, it becomes evident that methicillin sensitive Staph. aureus is the consistent pathogen in various forms of cutaneous pyodermas.

Staph. aureus, the most common culture isolate was found to be sensitive to cloxacillin in $100 \%$ of the isolates, $1^{\text {st }}$ generation cephalosporins in $94.11 \%$ cases, amikacin in $73.53 \%$ cases and gentamicin in $58.82 \%$ cases. All the MRSA isolated were sensitive to vancomycin, amikacin and linezolid.

The kappa coefficient value showing the strength of agreement between the results of direct microscopy using Gram stain and culture in this study was 0.667 . This substantial agreement between these two may provide the valuable information, that in resource poor settings Gram stain may be adequate in determining the causative organism. 


\section{CONCLUSION}

This descriptive study on pyoderma in children showed the impetigo contagiosa as the commonest type. The important observations which resulted from this study different from previous similar studies included lymphocytosis instead of neutrophilia, lower frequency of raised ASO titre in streptococcal pyodermas and lower percentage of streptococci isolated in culture. Other important observations included predominance of methicillin sensitive Staph. aureus in most of the clinical types of pyoderma sensitive to cloxacillin and MRSA in $9.52 \%$ of the study population sensitive to vancomycin, amikacin and linezolid. Also the substantial agreement between Gram stain and culture highlights the importance of Gram stain in aetiological diagnosis in resource poor settings.

\section{REFERENCES}

[1] Craft N. Superficial cutaneous infections and pyodermas. In: Goldsmith LA, Katz SI, Gilchrest BA, et al. eds. Fitzpatrick's dermatology in general medicine. $8^{\text {th }}$ edn. Vol. 2. New York: McGraw Hill Publishing Inc., 2012:2128-47.

[2] Choi S. Bacterial skin infections. In: Arndt KA, Hsu JTS. eds. Manual of dermatologic therapeutics. $7^{\text {th }}$ edn. Philadelphia: Lippincott Williams \& Wilkins 2007: 31-6.

[3] Thappa DM. Clinical paediatric dermatology. Chapter 8. Bacterial infections. Noida: Elsevier 2009:43-9.

[4] James WD, Berger TG, Elston DM. Andrew's diseases of the skin. Chapter 14. Bacterial infections. $11^{\text {th }}$ edn. Philadelphia: Saunders Elsevier 2011:247-86.
[5] Mathew SM, Garg BR, Kanungo R. A clinicobacteriological study of primary pyodermas of children in Pondicherry. Indian J Dermatol Venereol Leprol 1992;58(3):183-7.

[6] Nagmoti MJ, Patil CS, Metgud SC. A bacteriological study of pyoderma in Belgaum. Indian J Dermatol Venereol Leprol 1999;65(2):69-71.

[7] Kakar N, Kumar V, Mehta G, et al. Clinicobacteriological study of pyodermas in children. J Dermatol 1999;26(5):288-93.

[8] Kharel C, Pandey SS, Agarwal S, et al. Socioeconomic and nutritional status of children with pyodermas. Nep J Dermatol Venereol Leprol 2012;10(1):11-5.

[9] Kar PK. A combination of amoxicillin and clavulanic acid in the treatment of pyoderma in children. Indian J Dermatol Venereol Leprol 1996;62(2):91-4.

[10] Ahmed K, Batra A, Roy R, et al. Clinical and bacteriological study of pyoderma in JodhpurWestern Rajasthan. Indian J Dermatol Venereol Leprol 1998;64(3):156-7.

[11] Patil R, Baveja S, Nataraj G, et al. Prevalence of Methicillin Resistant Staphylococcus Aureus (MRSA) in community-acquired primary pyoderma. Indian J Dermatol Venereol Leprol 2006;72(2):126-8.

[12] Tushar S, Tanuja J, Sangeetha $P$, et al. Clinicobacteriological study of pyoderma with special reference to community acquired methicillin resistant Staphylococcus aureus. Natl J Integrated Res Med 2012;3(1):21-5. 